\title{
Ergonomics, automation and logistics: practical and effective combination of working methods, a case study of a baking company
}

\author{
Leonardo Quintana ${ }^{\mathrm{a}, *}$, Claudia Arias ${ }^{\mathrm{b}}$, Jorge Cordoba $^{\mathrm{b}}$, Magda Moroy $^{\mathrm{b}}, \mathrm{Jean}$ Pulido $^{\mathrm{b}}$, Angela Ramirez \\ ${ }^{a}$ Ergonomics Studies Center, Javeriana University, calle 40 N5-37,Phone Number 571-320-8320 ext.5351, \\ Bogota, Colombia \\ ${ }^{\mathrm{b}}$ Ergonomics Studies Center, Javeriana University, calle $40 N^{\circ} 5-37$, Bogota, Colombia
}

\begin{abstract}
The aim of this study was to combine three different analytical methods from three different disciplines to diagnose the ergonomic conditions, manufacturing and supply chain operation of a baking company. The study explores a summary of comprehensive working methods that combines the ergonomics, automation and logistics study methods in the diagnosis of working conditions and productivity. The participatory approach of this type of study that involves the feelings and first-hand knowledge of workers of the operation are determining factors in defining points of action and ergonomic interventions, as well as defining opportunities in the automation of manufacturing and logistics, to cope with the needs of the company. The study identified an ergonomic situation (high prevalence of wrist-hand pain), and the combination of interdisciplinary techniques applied allowed to improve this condition in the company. This type of study allows a primary basis of the opportunities presented by the combination of specialized methods of different disciplines, for the definition of comprehensive action plans for the company. Additionally, it outlines opportunities for improvement and recommendations to mitigate the burden associated with occupational diseases and as an end result improve the quality of life and productivity of workers.
\end{abstract}

Keywords: Ergonomics, manufacturing, discomfort, bakeries, working conditions, interventions

* Corresponding author, E-mail: lquin@javeriana.edu.co 


\section{Introduction}

The combination of working methods to diagnose human system, machine / object and physical space of a bakery company, was studied. According to the report of Sample Monthly Manufacturing Industry of Colombia Food and Drink, presented by DANE in 2008, the baking industry was the second highest contribution to the personnel employed in Colombia. In 2007 came comprise $16.88 \%$ of total employment in the food sector and beverages in Colombia (DANE, 2008).

As the sector has been growing and expanding interesting, so the presence of occupational diseases has increased in recent years and established as the main causes of occupational morbidity in the country (Ministry of Social Protection, 2003). Given this circumstance, it was decided to make a study of working conditions on occupational ergonomics, to propose possible solutions for change in the company to mitigate the burden associated with occupational diseases, improve the quality of life and productivity of workers, an analysis of the areas of production and distribution centers and likewise, we analyzed the supply chain and examined the possibilities of implement automation in some processes.

\section{Methodological Formulation}

In this study, 712 people (202 women and 510 men) were recruited. Three diagnostic methods were used to develop the study:

1- In logistics, a survey aimed to collect the most important management concept of the company that is based on self-reports of emerging literature.

2- Ergonomics, data collection method for the study of musculoskeletal disorders, known as the Nordic questionnaire, developed by Kuorinka et al. (1987). Variables such as age, shift, gender, seniority,

The effective combination of methods allowed to analyze the occupational health problem, using the methodology as a tool product of this interdisciplinary work in the logistics process innovation, ergonomic design and automation, where discipline takes into account the results of others to develop effective practices and without risk to humans.

Thanks to this we were able to recommend some improvements to the company, mainly the implemen- reported discomfort, gender and areas in the company, were studied. Self-report was adapted to the information needs of the Company.

Finally, all analyses were processed through SPSS software.

\section{Case Study}

The results of the study were divided into two parts according to the methods used.

1- We succeeded in identified the operational processes of the company, and the critical areas such as the baking one. Knowing the critical processes and areas of the company was very useful in order to focus in those areas that were more likely to be linked to the presence of pain and occupational diseases.

2- The ergonomic conditions studied using self-report were: analysis by gender and area of the company, analysis by gender, shift and discomfort gender, age and length analysis, analysis by areas, details of other issues now reported and Physician Occupational. We found that the main pain reported by the workers was in the wrist-hand $(44,5 \%$ of the sampled workers reports this condition).

Table 1

\begin{tabular}{|c|c|c|c|c|}
\multicolumn{5}{|c}{ Population Description } \\
\hline Variable & Average & $\begin{array}{c}\text { Standard } \\
\text { deviation }\end{array}$ & P10 & P90 \\
\hline Age & 35,03 & 10,27 & 22,00 & 48,00 \\
\hline Weight & 65,40 & 10,18 & 52,00 & 79,00 \\
\hline Height & 1,66 & 0,08 & 1,55 & 1,75 \\
\hline $\begin{array}{c}\text { Years in the } \\
\text { work }\end{array}$ & 10,09 & 8,39 & 0,67 & 21,18 \\
\hline $\begin{array}{c}\text { Years on the } \\
\text { job }\end{array}$ & 6,73 & 6,87 & 0,50 & 16,00 \\
\hline
\end{tabular}

tation of rest periods, the relocation of those workers who are more likely to suffer the specific pain detected with the self-reports and the re-design of some processes. The benefits of this improvement were significant, because a few months later the supervisors reported that the prevalence of the wrist-hand pain had diminished from $44,5 \%$ to $24,5 \%$. 


\section{Discussion and Conclusions}

Different methods of evaluation and diagnosis of bakery companies exist in the literature. Combined methods that allow assess the system human, machine / object and physical space for enterprises that allow effective intervention and complementary disciplines, have a low rate of occurrence. This study shows an interdisciplinary approach applied to the logistics process innovation, ergonomic design and automation, using validated methods of direct observation. The study additionally shows data with a significant sample of the main problems, facing workers in a baking company and potential opportunities for improvement. 


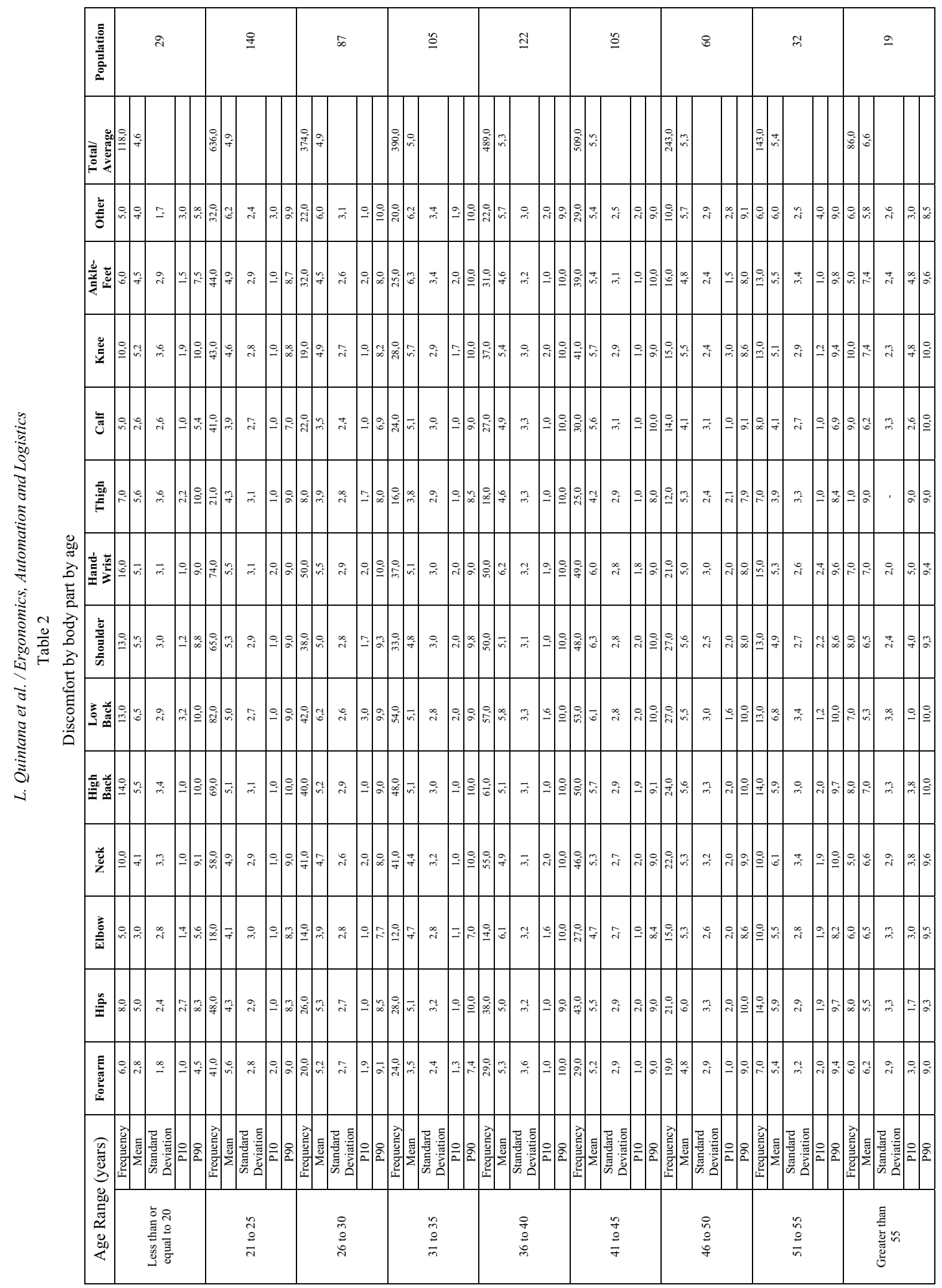

